\title{
Surface passivation in diamond nucleation
}

\author{
C. H. Lee, Z. D. Lin, N. G. Shang, L. S. Liao, I. Bello, N. Wang, and S. T. Lee* \\ Center of Super-Diamond \& Advanced Films (COSDAF) and Department of Physics \& Materials Science, \\ City University of Hong Kong, Hong Kong, China
}

(Received 15 December 1999)

\begin{abstract}
Surface passivation is introduced to suppress the deleterious effect of Si surface oxides and thus enhance diamond heteroepitaxial nucleation. Surface composition and diamond nucleation and growth on $\mathrm{H}-, \mathrm{Br}-$, and I-passivated Si surfaces were studied. X-ray photoelectron spectroscopy showed that the passivated Si surfaces were free of silicon oxides and carbides. Remarkable enhancement in nucleation was achieved on passivated surfaces and the nucleation density obtained on a Br-passivated Si surface reached $10^{10} \mathrm{~cm}^{-2}$. Programmable temperature desorption revealed that the adsorbate desorption temperature increased in the order of $\mathrm{H}, \mathrm{I}$, and $\mathrm{Br}$ passivation. The same order of increase was also observed in the saturation value of electron emission current from the passivated surfaces, which was related to the degree of nucleation. Nucleation enhancement was shown to be greater when the adsorbate desorption temperature is closer to the nucleation temperature, so that more adsorbate- and oxide-free Si surface area would be available for nucleation. The study established that surface passivation is potentially an effective approach for diamond heteroepitaxial nucleation.
\end{abstract}

\section{INTRODUCTION}

Large-area epitaxial single crystalline diamond film has long been expected since the highly oriented polycrystalline diamond films were grown heteroepitaxially on Si by Jiang et $a{ }^{1}{ }^{1}$ Despite the intensive effort devoted to the epitaxial growth of diamond film on $\mathrm{Si}$, little progress has been made since the early success. ${ }^{1}$ One of the reasons that epitaxial single crystalline diamond films cannot be achieved is possibly due to the fact that the $\mathrm{Si}$ surface is very reactive and a thin oxide layer $\left(\mathrm{SiO}\right.$ or $\left.\mathrm{SiO}_{2}\right)$ forms easily on the surface. Even when starting with a clean Si surface, the trace amount of oxygen and water vapor in the growth chamber may induce the formation of oxide layer, which inhibits the epitaxial growth and may eventually suppress diamond deposition. As such, it is unlikely that a single crystalline diamond film can be deposited on a partially oxidized Si surface.

The scanning Auger microscopy results of Tanaka et al. ${ }^{2}$ showed that diamond nuclei were competitively deposited with silicon oxide on the Si surface. Therefore, removal of oxide on the $\mathrm{Si}$ surface may effectively enhance diamond growth, as pointed out by Bergmaier et al. ${ }^{3}$ Because diamond nucleation and growth by chemical vapor deposition (CVD) were achieved in an $\mathrm{H}_{2}$ environment, a small amount of oxygen would normally be acceptable in diamond growth. However, Schreck et al. ${ }^{4}$ found that the introduction of 75 ppm of $\mathrm{CO}_{2}$ (corresponding to a $\mathrm{C}: \mathrm{O}$ ratio of $600: 1$ ) into the gas mixture would seriously suppress the nucleation and growth area of diamond. Kang et al. ${ }^{5}$ also revealed that increasing oxygen contamination in the reactant gases greatly reduced the diamond nucleation density on $\mathrm{Si}$. Thermodynamically, a hydrogen/oxygen ratio greater than $10^{6}$ would be necessary to reduce $\mathrm{CO}_{2}$ thermally at 1 bar and at a temperature typical for diamond CVD growth, i.e., 800-900 ${ }^{\circ}$. $^{3}$

Generally, the $\mathrm{H}_{2}$ source contains a very small amount of $\mathrm{O}_{2}$ and $\mathrm{H}_{2} \mathrm{O}$, while the base pressure of a CVD chamber is typically larger than $10^{-7}$ torr. As a result, the trace amount of $\mathrm{O}_{2}$ and $\mathrm{H}_{2} \mathrm{O}$ present in the $\mathrm{H}_{2}$ and $\mathrm{CH}_{4}$ sources and/or the residual ambient during CVD growth not only compensates the reduction process by the activated hydrogen but further leads to new oxidation of the Si surface.

The oxide layer can be partially removed by positive ion bombardment on the Si substrate through the applied negative bias voltage, as suggested by Yugo et al. ${ }^{6}$ However, diamond heteroepitaxy would be difficult due to the damage of lattice structure caused by ion bombardment. Thus, the positive and negative effects of ion bombardment coexist simultaneously. To compromise between the positive and negative effects of bias, the time for ion bombardment at a certain energy has to be limited in a certain range (time window). ${ }^{7}$ Furthermore, it is difficult to remove the oxide layer completely with unlimited ion bombardment. The partial removal of the oxide layer thus restricts heteroepitaxial growth to local regions.

In order to grow large-area diamond epitaxy, the surface oxide must be removed completely from the Si wafer before and during the nucleation and growth process. Or the oxygen effect at least should be minimized to a negligible level. To eliminate the oxygen effect, surface cleaning, and passivation of the Si substrate, purification of the hydrogen source and improvement of the chamber vacuum level are all useful and essential. This work represents an investigation of the effect of Si surface passivation on diamond nucleation and growth.

\section{EXPERIMENTAL DETAILS}

Diamond nucleation and growth were performed in a microwave plasma chemical vapor deposition (MP-CVD) system (from ASTEX ${ }^{\mathrm{TM}}$ ). The base pressure in the deposition chamber was $5 \times 10^{-7}$ torr. The substrates were placed on a graphitic substrate holder, which was inductively heated. The temperature of the substrate holder, measured by the thermocouple, was used to control the power of the induction heater. The substrates were mirror-polished $p$-type (111) Si wafers, 3-in. in diameter and with a resistivity of $7 \Omega \mathrm{cm}$. 


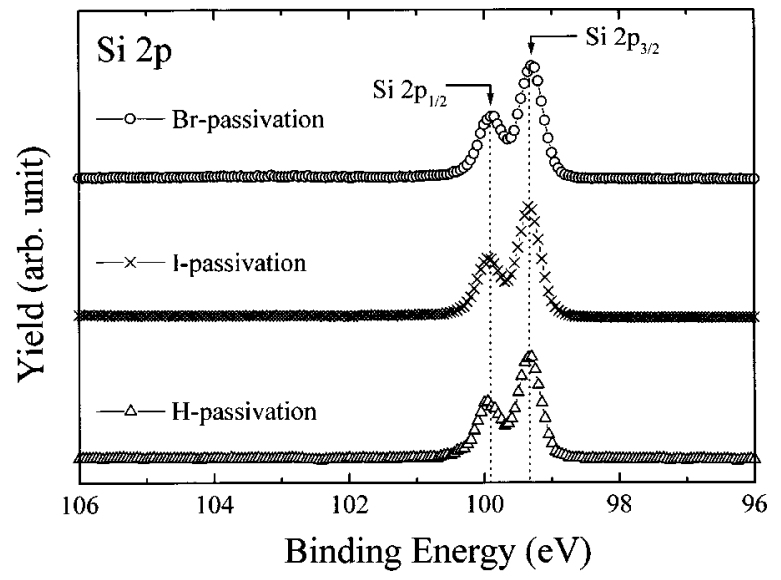

FIG. 1. XPS Si $2 p$ core-level spectra taken from $\mathrm{H}-$, $\mathrm{Br}-$, and I-passivated $\mathrm{Si}$, respectively.

The substrate was cleaned ultrasonically in acetone, ethanol, and deionized water for $10 \mathrm{~min}$, respectively, then immersed in $20 \% \mathrm{HF}$ solution for $2 \mathrm{~min}$ to remove the native oxide. The wafer was then treated with a $\mathrm{H}_{2} \mathrm{O}_{2}: \mathrm{HCl}: \mathrm{H}_{2} \mathrm{O}$ (in a volume ratio of 3:1:1) solution for $5 \mathrm{~min}$ for reoxidation and immersed in a HF: $\mathrm{NH}_{4} \mathrm{E}(1: 3)$ solution for 8 min to remove oxide. Finally, the Si wafer was rinsed with deionized water. The above cleaning procedure gives $\mathrm{Si}$ substrates with $\mathrm{H}$ passivation. ${ }^{8}$ By spraying the $\mathrm{H}$-passivated $\mathrm{Si}$ substrate with $\mathrm{Br}$ methanol or I methanol under dry $\mathrm{N}_{2}$ atmosphere, $\mathrm{Br}-$ passivated and I-passivated $\mathrm{Si}$ substrates were obtained, respectively. ${ }^{9}$

The nucleation density and surface morphology of diamond were characterized by scanning electron microscopy (SEM, PHILIPS XL-30 FEG). Meanwhile, to evaluate the diamond nucleation density over the whole substrate area, we monitored the time dependence of the biasing current to determine the nucleation behavior and total area of diamond nuclei of the passivated $\mathrm{Si}$ substrates, as suggested by Schreck et al. ${ }^{4,10}$ To characterize the as-grown products, we used Raman spectroscopy (taken by Renishaw Raman System 2000), with a spectral resolution of $1 \mathrm{~cm}^{-1}$ and a spatial resolution of $1 \mu \mathrm{m}$. For checking surface cleanliness, XPS (VG ESCALAB 220i-XL) with a $\mathrm{Mg} K \alpha$ x-ray source was used. The pass energy was kept at $20 \mathrm{eV}$ giving an energy resolution of $0.5 \mathrm{eV}$.

\section{RESULTS AND DISCUSSION}

\section{A. Surface cleanliness of Si under different surface treatment}

Figure 1 shows the XPS spectra of $\mathrm{H}-,, \mathrm{Br}-$, and I-passivated $\mathrm{Si}$ surfaces. No $\mathrm{SiO}_{x}$ or $\mathrm{SiC}$ peaks were detected, while only the Si $2 p_{1 / 2}$ and $\mathrm{Si} 2 p_{3 / 2}$ peak components appeared in the spectra. This indicates that the Si surface was free of oxides and carbides. Therefore, it can be concluded that by using the surface passivation method we were able to obtain a fairly clean surface of Si. In the survey XPS spectrum, however, a small amount of oxygen and carbon was found in addition to $\mathrm{Si}, \mathrm{Br}$, or I. Although oxygen and carbon were detected after chemical cleaning, the trace amount of oxygen and carbon was probably physically adsorbed rather than directly bonded to the surfaces of the $\mathrm{H}-, \mathrm{Br}-$, and I-passivated $\mathrm{Si}$ substrate as no $\mathrm{Si}$ oxide and carbide peaks

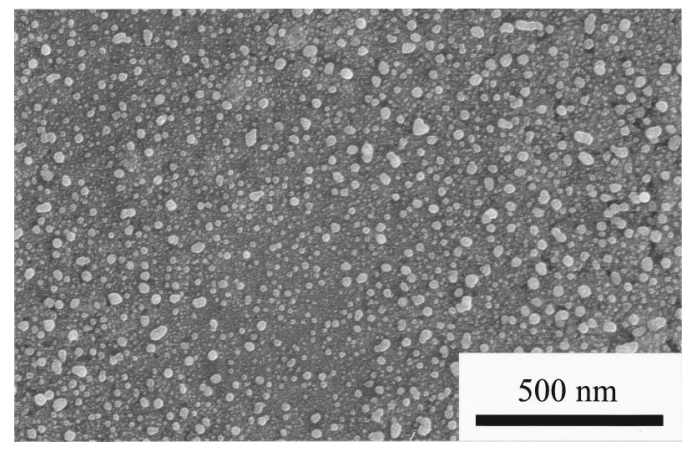

FIG. 2. Diamond nucleation density on Br-passivated Si substrate. Temperature, $620^{\circ} \mathrm{C}$; nucleation time, $30 \mathrm{~min}, \mathrm{CH}_{4} / \mathrm{H}_{2}$ $=1 \%$; microwave power, $1000 \mathrm{~W}$.

were detected in the Si $2 p$ spectrum. To remove the adsorbed oxygen and carbon traces, a low-temperature pretreatment ${ }^{11,12}$ was carried out before diamond nucleation. The process was achieved in the MP-CVD chamber by using a $1 \% \mathrm{CH}_{4} / \mathrm{H}_{2}$ gas mixture, a microwave power of $600 \mathrm{~W}$, and a substrate temperature of $220^{\circ} \mathrm{C}$ for $30 \mathrm{~min}$.

\section{B. Effect of Si surface passivation on diamond nucleation}

Figure 2 shows the SEM picture of the nuclei density on a Br-passivated Si substrate. After removal of surface oxygen and carbon as mentioned above, the substrate temperature was increased to $620^{\circ} \mathrm{C}$ for nucleation and the time was kept at $30 \mathrm{~min}$. The gas mixture used was $\mathrm{CH}_{4} / \mathrm{H}_{2}=1 \%$ and the microwave power was 1000 W. From Fig. 2, the nucleation density was measured to be $6 \times 10^{10} \mathrm{~cm}^{-2}$, which is comparable to the highest nucleation density level of 5 $\times 10^{10} \mathrm{~cm}^{-2}$ obtained under $200 \mathrm{~V}$ negative bias treatment reported by Stoner et al. ${ }^{11}$ The grown surface species was characterized by Raman spectroscopy. Besides the characteristic diamond peak at $1332 \mathrm{~cm}^{-1}$, the graphite peak at 1580 $\mathrm{cm}^{-1}$ is also present in Fig. 3(a). After a continuous growth of $5 \mathrm{~h}$ at $620^{\circ} \mathrm{C}$, the sharp diamond peak became dominant in the spectrum and the graphite peak was hardly detectable [Fig. 3(b)]. The morphology of the as-grown diamond is shown in Fig. 4, which shows the typical polycrystalline CVD diamond film. It is important to point out that extremely high nucleation density was obtained without applying a bias voltage to the $\mathrm{Si}$ substrate and at a comparatively low temperature of $620^{\circ} \mathrm{C}$. Why can such a high nucleation density be achieved on Br-passivated Si substrate? We believe that the main reason lies in the fact that $\mathrm{Br}$ was able to effectively prevent the Si surface from oxidation until it de-

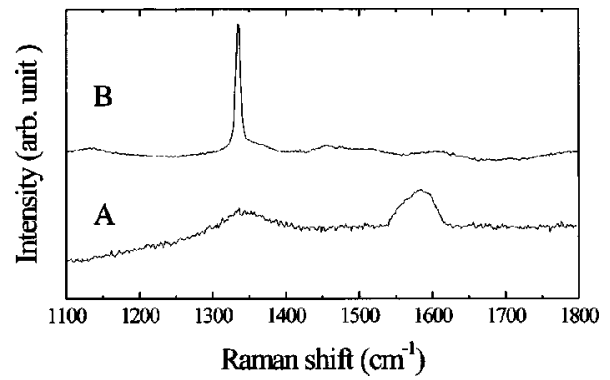

FIG. 3. Raman spectra of diamond nucleation $(A)$ and growth (B) on Br-passivated Si. 


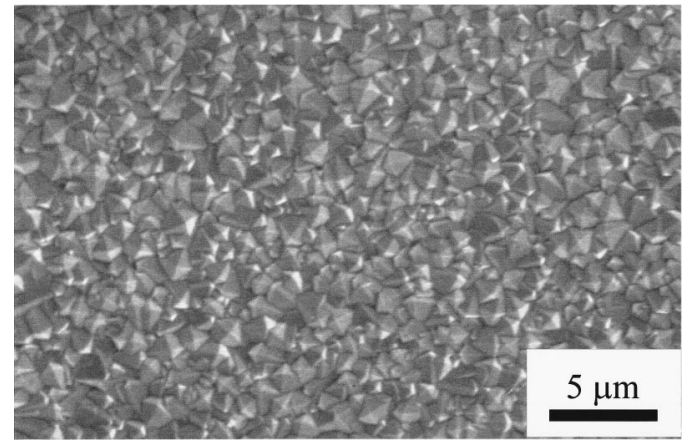

FIG. 4. SEM of Fig. $3(B)$ sample after growing for $5 \mathrm{~h}$.

sorbed from the surface. The desorption temperature of $\mathrm{Br}$ was comparatively high at $578{ }^{\circ} \mathrm{C}$ (shown in Fig. 5), as measured by a temperature programmable quadrupole mass spectrometer. As a result, $\mathrm{Br}$ species would only start to desorb when the $\mathrm{Si}$ substrate temperature was close to $620^{\circ} \mathrm{C}$, where diamond nucleation would initiate. The time elapse between $\mathrm{Br}$ desorption and diamond nucleation was very short, thus minimizing the oxidation probability of Si. Since diamond would easily nucleate on the fresh $\mathrm{Si}$ surface free of oxygen, the resulting diamond nucleation density would be high. If the Si surface were H-passivated, the situation would be quite different. Since the desorption temperature of $\mathrm{H}$ on the Si surface was $258^{\circ} \mathrm{C}$ (shown in Fig. 5), hydrogen would have been completely desorbed as the temperature ramped up to $620^{\circ} \mathrm{C}$ from $258^{\circ} \mathrm{C}$. The time elapse between $\mathrm{H}$ desorption and diamond nucleation would be comparatively longer than that for the Br-passivated Si surface. Since a small amount of $\mathrm{O}_{2}$ and water vapor was inevitably present in the growth chamber (with a base pressure at 5 $\times 10^{-7}$ torr and the gas reagent used), oxidation would be
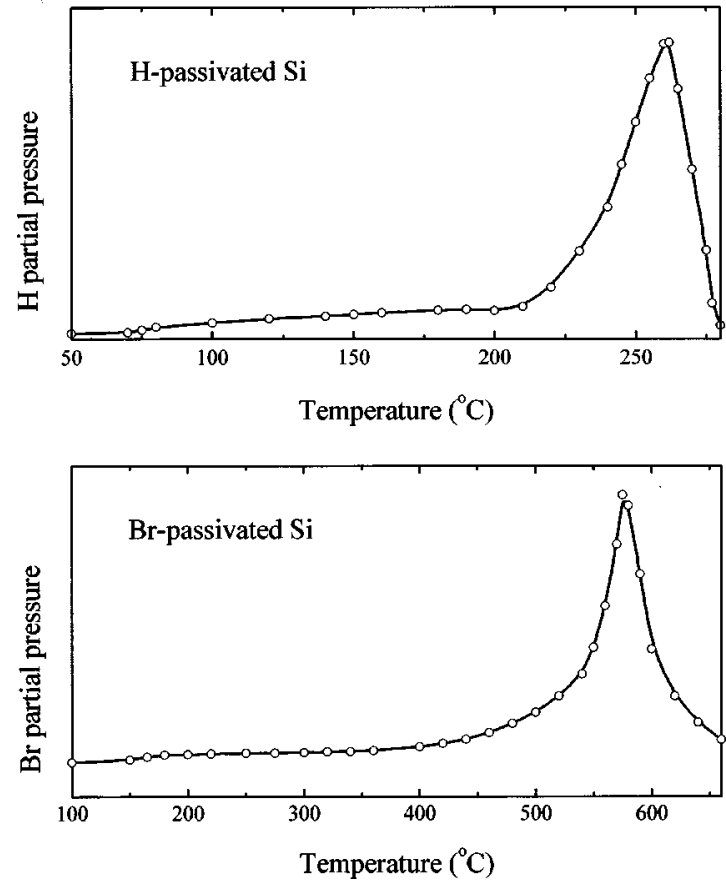

FIG. 5. Temperature programming desorption curves for $\mathrm{H}$ and $\mathrm{Br}$ on $\mathrm{Si}(111)$; measured by QMS. Temperature rises in a rate of $2.5^{\circ} \mathrm{C} / \mathrm{min}$. appreciable for a $\mathrm{H}$-passivated $\mathrm{Si}$ surface at the nucleation temperature. As the surface oxide would obstruct diamond nucleation, diamond nucleation density would thus be comparatively low, generally in the range of $10^{6}-10^{8} \mathrm{~cm}^{-2}$.

The oxygen effect also plays a role in other nucleation enhancement. Recently, Kang et al..$^{5}$ reported that under the condition of $10^{-10}$ torr base pressure and high-purity $\mathrm{H}_{2}$ gas, a diamond nucleation density of $10^{10} \mathrm{~cm}^{-2}$ was obtained on a mirror-polished Si surface with no negative bias. However, if $0.16 \% \mathrm{O}_{2}$ were added to the gas mixture, the nucleation density would drop to $10^{7} \mathrm{~cm}^{-2}$. In the bias-enhanced nucleation method, ${ }^{1,6,11}$ positive ion bombardment can partially remove the oxide layer on the Si surface. Since diamond can nucleate readily on oxide-free $\mathrm{Si}$ surfaces, nucleation density may thus increase to $10^{10}-10^{11} \mathrm{~cm}^{-2}$. On the other hand, ion bombardment-induced damage and partial surface oxide removal disrupt the periodicity of the surface lattice structure, therefore epitaxial nucleation is eventually difficult over a large area..$^{13,14}$

To further elucidate the effect of surface passivation, diamond nucleation on the I-passivated $\mathrm{Si}$ surface was also studied. No prominent enhancement effect was found for nucleation on I-passivated $\mathrm{Si}$ at $620^{\circ} \mathrm{C}$. This can be explained by the fact that the desorption temperature of I was much lower than that of $\mathrm{Br}$ but higher than that of $\mathrm{H}$. Although we could not measure the desorption temperature of I (the mass of $\mathrm{I}$ is beyond the measurement range of our QMS), we estimated it from the binding energy of the Si-I and $\mathrm{Si}-\mathrm{Br}$ bonds $\left(293\right.$ and $367.8 \mathrm{~kJ} / \mathrm{mol}$, respectively $\left.{ }^{15}\right)$ to be around $460^{\circ} \mathrm{C}$. Consequently, as the substrate temperature ramped up to $620^{\circ} \mathrm{C}$, iodine would have been completely desorbed from the Si surface and the Si surface exposed to oxidation by the CVD ambient well before nucleation started at $620{ }^{\circ} \mathrm{C}$. Therefore, the diamond nucleation density on I-passivated $\mathrm{Si}$ was intermediate between those on $\mathrm{H}$-passivated and Br-passivated Si surfaces.

\section{Comparison of substrate biasing current with different $\mathrm{Si}$ surface passivation}

Since the electron emission from a diamond surface is much stronger than from a bare Si surface, an increase in current under negative substrate bias during the nucleation process can be correlated to the diamond coverage on a $\mathrm{Si}$ wafer, as discussed by Schreck et al. ${ }^{4,7}$ Therefore, the temporal evolution of bias-induced substrate current provides an insight into the diamond nucleation behavior while the saturation value of biasing current gives an estimate of the relative diamond coverage on $\mathrm{Si}$. The experimental details are as follows. The passivated $\mathrm{Si}$ substrate was kept at $510^{\circ} \mathrm{C}$, slightly lower than the desorption temperature of $\mathrm{Br}$, and applied with a $180-\mathrm{V}$ negative bias under a $3 \%, \mathrm{CH}_{4} / \mathrm{H}_{2}$ gas ambient and a microwave power of $1200 \mathrm{~W}$. Figure 6 depicts the time dependence of the biasing current from the passivated Si surfaces. Comparison of the three curves shows two distinct features. First, the bias current increased rapidly to a saturation value after 240 min for the H-passivated sample. For the Br-passivated sample, the change in bias current versus nucleation time was relatively slow compared to the H-passivated sample. It took approximately seven hours to reach its saturation value. The rate of increase in bias current 


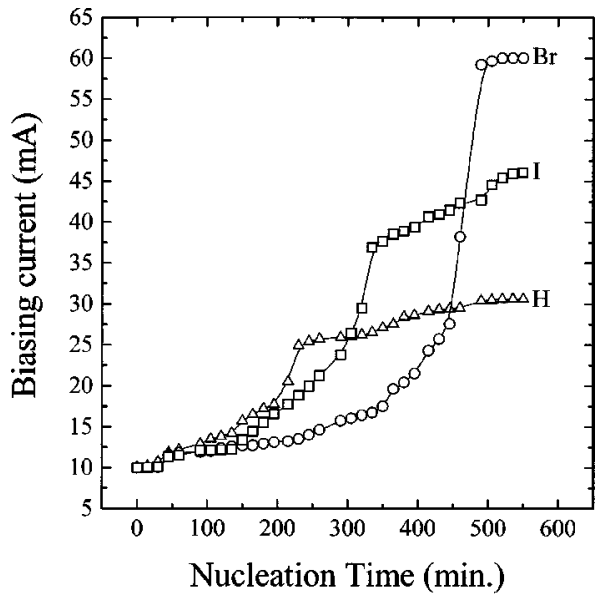

FIG. 6. Temporal evolution curves of induced biasing current for $\mathrm{Si}$ substrates passivated by bromine $(\mathrm{Br})$, passivated by iodine $(\mathrm{I})$, and passivated by hydrogen $(\mathrm{H})$ during diamond nucleation.

for the I-passivated sample was less than that of the Br- and $\mathrm{H}$-passivated samples. Second, the value of the saturation bias current was in the order of $\mathrm{H}$ passivation less than I passivation less than $\mathrm{Br}$ passivation, with the Br-passivated sample having the highest saturation bias current. This indicates that the Br-passivated Si substrate had the largest coverage of diamond nuclei among the three.,

The two prominent features stated above are consistent with the nucleation behavior of the three passivated $\mathrm{Si}$ substrates. Owing to the ease of $\mathrm{H}$ desorption at temperatures below $510^{\circ} \mathrm{C}$, the $\mathrm{Si}$ substrate would be exposed first and nucleation would start earliest on the H-passivated $\mathrm{Si}$, as evidenced by a rapid increase in bias current. This is consistent with the results reported by Schreck et al. ${ }^{4,7}$ For the Br-passivated sample, since the substrate temperature $\left(510^{\circ} \mathrm{C}\right)$ was slightly $\left(68^{\circ} \mathrm{C}\right)$ lower than the $\mathrm{Br}$ desorption temperature $\left(578^{\circ} \mathrm{C}\right), \mathrm{Br}$ desorption would be slow, although it could be assisted by ion bombardment. As a result, the $\mathrm{Si}$ surface would be exposed very slowly and diamond nucleation would begin very late, as evidenced by the slow increase of biasing current at $7 \mathrm{~h}$ (Fig. 6). The explanation for the trend of the saturation bias current follows similarly. At $510^{\circ} \mathrm{C}, \mathrm{H}$ desorption has long completed; the probability of $\mathrm{Si}$ substrate exposure to oxygen in the chamber is high. Consequently, the nucleation process will soon be blocked and the area covered by nuclei is small. For the Br-passivated $\mathrm{Si}$ surface, $\mathrm{Br}$ desorption was primarily induced by cation bombardment. Moreover, during the bombardment, diamond was formed simultaneously. Therefore, the probability of the bare Si surface being exposed to oxygen would be very low. As a result, an increase in nucleation area and thus the largest saturation bias current were observed. These results are in good agreement with the SEM pictures of nucleated Si.

\section{CONCLUSIONS}

One difficulty for diamond epitaxial nucleation on $\mathrm{Si}$ was the competition between diamond nucleation and surface oxidation on Si. By minimizing surface oxidation during the nucleation process, surface passivation of $\mathrm{Si}$ has been shown to be an effective method for nucleation enhancement. We compared the effect of $\mathrm{H}, \mathrm{I}$, and $\mathrm{Br}$ passivation on diamond nucleation and concluded that $\mathrm{Br}$ passivation gave rise to the highest nucleation enhancement. Nucleation density on $\mathrm{Br}-$ passivation Si reached a level of $10^{10} \mathrm{~cm}^{2}$, which is comparable to the highest value obtained thus far by the biasenhanced nucleation method.

\section{ACKNOWLEDGMENTS}

We express our sincere thanks to T. F. Hung in the SEM work. This work was partially supported by Hong Kong RGC (Project No. 9040358) and the SRG of City University of Hong Kong (Project No. 9040343).
*Author to whom correspondence should be addressed. Electronic mail: apannale@cityu.edu.hk

${ }^{1}$ X. Jiang, K. Schiffmann, A. Westphal, and C. P. Klages, Appl. Phys. Lett. 63, 1203 (1993).

${ }^{2}$ S. Tanaka, K. Ikoma, H. Kiyota, J. Tanaka, M. Kamo, and Y. Sato, in Advances in New Diamond Science and Technology, edited by S. Saito, N. Fujimori, O. Funkunaga, M. Kamo, K. Kobashi, and M. Yoshikawa (MYU, Tokyo, 1994), p. 481.

${ }^{3}$ A. Bergmaier, M. Schreck, G. Dollinger, O. Schmelmer, K. H. Thürer, and B. Stritzker, Diamond Relat. Mater. 8, 1142 (1999).

${ }^{4}$ M. Schreck, K. H. Thürer, C. Christensen, M. Müller, and B. Stritzker, Diamond Relat. Mater. 8, 160 (1999).

${ }^{5}$ J. Kang, C. Xiao, Y. Xiong, Y. Xiang, Y. Wang, Q. Meng, Z. Lin, and K. Feng, Acta Phys. Sin. 48, 2104 (1999).

${ }^{6}$ S. Yugo, T. Kimura, and T. Muto, Appl. Phys. Lett. 58, 1036 (1991).
${ }^{7}$ M. Schreck, K. H. Thürer, R. Klarmann, and B. Stritzker, J. Appl. Phys. 81, 3096 (1997).

${ }^{8}$ T. Sakuri and H. D. Hagstrum, Phys. Rev. B 12, 5349 (1975).

${ }^{9}$ K. Sekar, P. V. Satyam, G. Kuri, D. P. Mahapatra, and B. N. Dev, Nucl. Instrum. Methods Phys. Res. B 71, 308 (1992).

${ }^{10}$ M. Schreck, T. Baur, and B. Stritzker, Diamond Relat. Mater. 4, 553 (1995).

${ }^{11}$ B. R. Stoner, G. H. M. Ma, S. D. Wolter, and J. T. Glass, Phys. Rev. B 45, 11067 (1992).

${ }^{12}$ Hiroshi Yamada, Jpn. J. Appl. Phys., Part 1 65, 775 (1989).

${ }^{13}$ X. Jiang, R. Q. Zhang, G. Yu, and S. T. Lee, Phys. Rev. B 58, 15351 (1998).

${ }^{14}$ R. Q. Zhang, W. J. Zhang, C. Sun, X. Jiang, and S. T. Lee, Diamond Relat. Mater. 8, 1418 (1999).

${ }^{15}$ Hichem M' Saad, Jurgen Michel, J. J. Lappe, and L. C. Kimerling, J. Electron. Mater. 23, 487 (1994). 